\title{
Fact or fable: Increased wellbeing in voluntary simplicity
}

\author{
Stacey Ann Rich · Sharon Hanna · Bradley J. Wright · Pauleen C. Bennett
}

\section{Introduction}

Aesop (trans. 2014) tells of a peacock - beautifully plumed and brightly coloured - who mocks a crane for his dull appearance. The crane points out that he does indeed appear quite plain, but, unlike the peacock, is able to soar to great heights. In this fable, Aesop wags his finger at the reader, warning that fine feathers do not make fine birds. Moreover, he asserts, sometimes appearing outwardly simple can belie inward riches. This is the view taken by many who engage in a lifestyle known as voluntary simplicity, a way of living that is described as "outwardly simple and inwardly rich" (Elgin \& Mitchell, 1977, p. 2). Indeed, the value of a simple life has been espoused by writers and thinkers throughout time, who have consistently proposed simplicity as a path to wellbeing. If this is a legitimate claim, society stands to benefit if a simple lifestyle becomes more widely adopted. But is it legitimate? The following review briefly considers what is meant by the terms "voluntary simplicity" and "wellbeing." We then ask the question: is there empirical evidence for an association between voluntary simplicity and improved wellbeing?

Voluntary simplicity (VS) - a term originally coined by Gregg (1936) - is the name given to a lifestyle whose hallmark is reduced material consumption. Elgin and Mitchell (1977) adopted Gregg's turn of phrase to describe certain characteristics they believed were common to various "alternative" lifestyles of the day. The authors volunteered five values of a VS lifestyle, the first being material simplicity, or consuming only that which is required to satisfy needs. Also proposed were human scale, a desire for smaller-scale living and working environments; selfdetermination, the desire to have greater control over life; ecological awareness, a recognition of the limit to resources and the impact of individual actions on the rest of the world; and personal growth, a desire to develop the inner life, be it intellectual or spiritual. The concept of voluntary simplicity touches many aspects of individual and societal life. Simplifiers tend to work reduced hours, reduce their consumption, commit time to volunteer roles, use energy differently and report being happier. As a result, the lifestyle has the potential to impact research across multiple disciplines, including organisational, social and clinical psychology, economics, sustainability and public policy. Understanding this lifestyle, therefore, is of interest to many.

In order to understand the lifestyle, an understanding of who simplifiers are is required. The term "voluntary simplicity" is typically limited to those from highly developed "western-style" cultures (Alexander \& Ussher, 2012, p. 83), whose circumstances could otherwise permit a life of abundance and material wealth, given that simplifiers (as they will be referred to here) are often reported to be highly educated and from middle class backgrounds (Brown \& Kasser, 2005; Elgin, 2010; Huneke, 2005). Despite this ability for material abundance, simplifiers commonly earn lower incomes than the general population (Brown \& Kasser, 2005) although this is not always the case (Alexander \& Ussher, 2012). Indeed, exceptions appear to be the rule within the VS 
lifestyle. There is no set of rules to be strictly followed, and the manner and degree to which the lifestyle is engaged in is up to the discretion of the individual (Gregg, 1936). For some, simplicity is a "coherently articulated philosophy" (Etzioni, 1998, p. 626). For others, the simplification process is accidental (McDonald, Oates, Young \& Hwang, 2006). As such, there are a myriad of ways in which the lifestyle manifests.

The variety of motivations reported for living simply almost outnumber the variety of expressions of the VS lifestyle. Concern for the environment, having time for oneself, improved health, and having more time for relationships and community are among some motivations listed by respondents to one multi-national survey of simplifiers (Alexander \& Ussher, 2012). Simplifiers also report major life events (Breen Pierce, 2000) as well as financial reasons (Alexander \& Ussher, 2012; Shama \& Wisenblit, 1984) as drivers of the decision to simplify. However, one concept that appears repeatedly in the literature is that of improved wellbeing.

Richard Gregg, the man credited with coining the term voluntary simplicity, described simplicity as a "kind of psychological hygiene" (Gregg, 1936, p. 25). Similarly, Elgin and Mitchell (1977) proposed that motivation to simplify is often driven by "the realistic possibility of finding more satisfying ways to live" (p. 30). Further, Breen Pierce (2000) proposed that "living simply can facilitate a life of balance, purpose and joy" (p. 24). The writings of these authors and others suggest that, for proponents of voluntary simplicity, the promise of increased wellbeing is an enticing aspect of the lifestyle. While many aspects of voluntary simplicity have been empirically investigated - including consumption behaviours (Shaw \& Moraes, 2009; Shaw \& Newholm, 2002), values (Shama \& Wisenblit, 1984) cognitive processes (Boujbel \& d'Astous, 2012; Daoud, 2011), environmental responsibility (Brown \& Kasser, 2005; Elgin, 2010), and self-identity (Grigsby, 2004; Kahl, 2012) - investigation of the link to wellbeing is limited to just a few studies.

Before reviewing these studies, it is instructive to consider what is meant by the term "wellbeing." It is generally described as a broad concept that covers many aspects of positive functioning (Ryan \& Deci, 2001). Two schools of thought have emerged within the wellbeing corpus: those of hedonic wellbeing and eudaimonic wellbeing. Hedonic wellbeing - or hedonia - refers to pleasure and the absence of pain and distress, of comfort and enjoyment; whereas eudaimonic wellbeing - or eudaimonia - refers to concepts such as growth, meaning, authenticity, engagement and excellence, among others (Huta \& Waterman, 2014; Ryan \& Deci, 2001). While viewed as separate concepts, wellbeing researchers recognise that both are important to understanding wellbeing as a whole (Huta \& Waterman, 2014; Seligman, 2012).

A large portion of the wellbeing literature to date has concentrated on life satisfaction. Life satisfaction (LS) is an individual's evaluation of the quality of their life and forms an important part of subjective wellbeing (Diener, Suh, Lucas, \& Smith, 1999). Where it sits within the eudaimonic and hedonic traditions is a matter of debate, but it appears to be treated by most psychologists as hedonic in nature (Huta \& Waterman, 2014). Life satisfaction is well researched, with 11,782 articles addressing life satisfaction in the PsychInfo database alone (accessed 25/04/2016). The Satisfaction with Life Scale (SWLS) (Diener, Emmons, Larsen, \& Griffin, 1985) is a frequently used measure of LS. In general, healthy, unincarcerated adults score above the neutral point on the Satisfaction with Life Scale (Pavot \& Diener, 2008).

Life satisfaction is not the only measure of wellbeing, and the brief description of wellbeing given here does not do the field justice. Many alternative conceptualisations can be found elsewhere (cf. Delle Fave 2014; Huta \& Waterman 2014; Ryan \& Deci 2001). The information provided above is sufficient for the purpose of the current review, however, literature in the area of voluntary simplicity is typically constrained to measurement of life satisfaction and perceived happiness. In the following analysis, we investigate if the available literature supports an 
association between voluntary simplicity and increased wellbeing, typically operationalised as life satisfaction. With authors describing increased wellbeing in the literature since 1936, a review and synthesis of evidence supporting the putative connection is long overdue. Such a synthesis may provide insight into whether claims of improved wellbeing are empirically justified.

\section{Method}

Investigation of voluntary simplicity spans many disciplines. Accordingly, the search for literature was designed to be broad. One database from each of three disciplines was investigated in the search for literature, these being PsychInfo (psychology) ProQuest Business (economics) and ProQuest Social Science (sociology). Figure 1 is a flow chart representing the search strategy utilised and the resultant pool of articles.

Figure 1. A flow chart of the review process

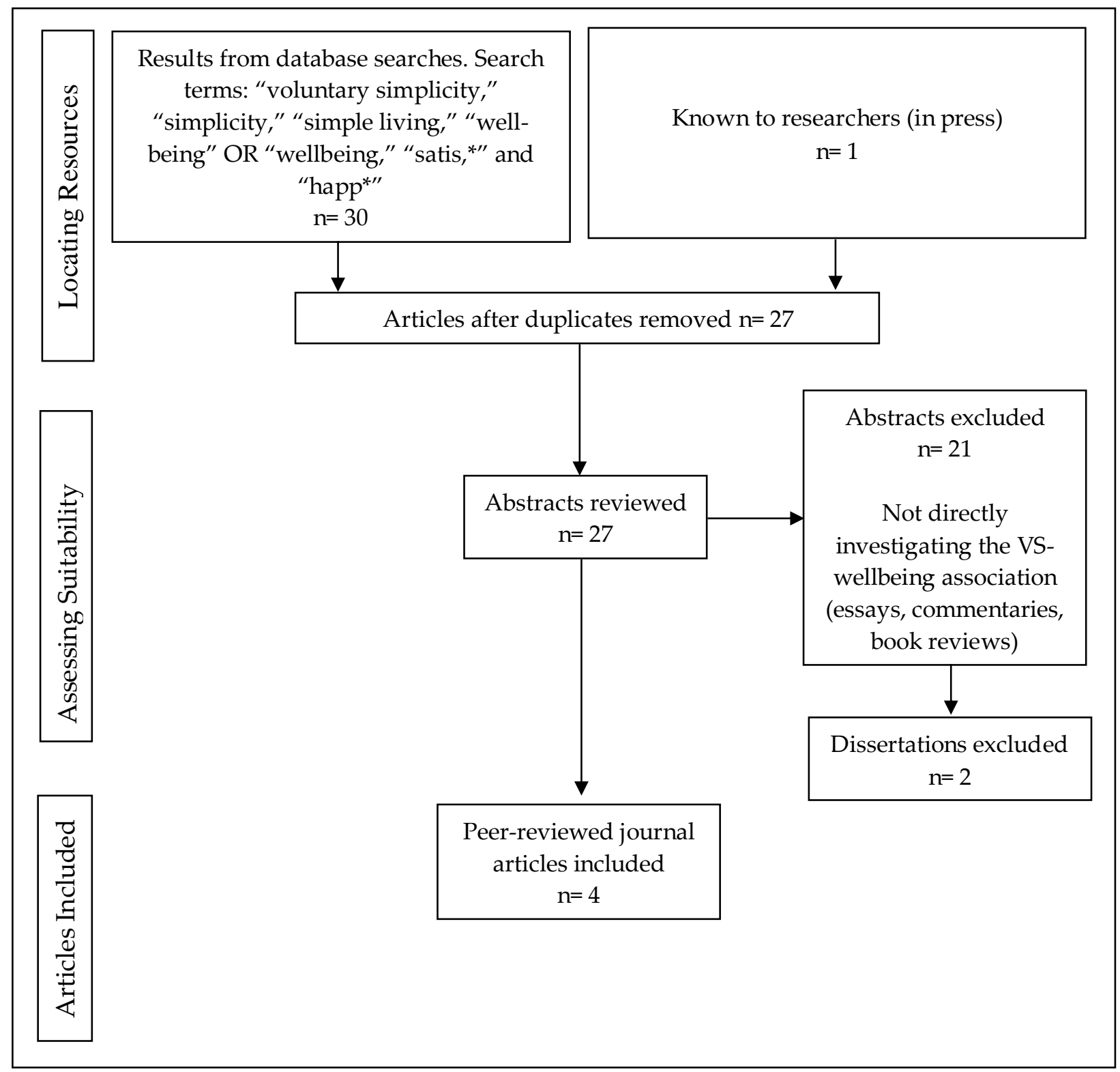

Articles were chosen based on whether they specifically looked at "voluntary simplicity," rather than at a broader conceptualisation of "a simpler life," and whether they specifically addressed 
wellbeing outcomes. Further, the search was restricted to peer-reviewed journal articles. It is important to note that, while the methodology was not confined to quantitative studies, we could find no qualitative studies directly addressing the wellbeing outcomes of voluntary simplifiers. That is not to say that such outcomes are not discussed in the qualitative literature. Concepts associated with wellbeing appear in the discourses of qualitative interviews, but are generally not the focus.

Our initial searches identified almost 30 relevant manuscripts, but when these were carefully assessed, it was found that only a few directly investigated the link between voluntary simplicity and wellbeing. Indeed, only three studies were located using the database searches described, these being Brown and Kasser (2005), Alexander and Ussher (2012), and Boujbel and d'Astous (2012). One additional article, in press at the time of writing, was also included, this being Rich, Hanna and Wright (2017). While the final pool of just four studies might be considered insufficient to support a comprehensive review, these studies contained wellbeing data for 3,233 participants, allowing a robust investigation of our central question.

\section{Results}

The results of the review are presented in the following sections. First, a table highlighting the characteristics of the four located studies is provided (Table 1 below). Drawing on this information, a critique and synthesis of the studies is then offered. This is followed by a statistical test of the relationship between voluntary simplicity and wellbeing, in the form of a metaanalytic procedure. Before reviewing the studies, some clarification of terminology is required. The term "mainstream" is commonly used in the voluntary simplicity literature to refer to those participants living what may be considered a more socially normative lifestyle. However, the term "mainstream" is very broad, covering many aspects of a dominant culture. For the current investigation, the term "non-simplifying participants" will be used as a comparison label, as voluntary simplicity is the main point of difference between the groups being referred to.

It is apparent from Table 1 that the studies reviewed are similar in many respects, such as sampling, demographics and measurement of wellbeing. The four studies, however, differed in how they identified voluntary simplifiers. The following is a brief discussion and synthesis of these similarities and differences.

\subsection{Sampling}

The four studies utilised similar methods to recruit their VS participants, with a large portion coming from web-based sources (Table 1). Statistics from 2014 suggest the United States (87.4\%) and Australia (84.6\%) have similar proportions of internet users (World Bank, n.d.). Although this represents a high proportion of the general population, internet usage is less likely for those with low income and the unemployed (Australian Bureau of Statistics, 2007). This may be problematic for the generalisability of the studies' findings. All four studies, however, employed other measures, such as magazines and letterbox drops, to reduce their reliance on internet-based recruitment and to find non-simplifying participants.

\subsection{Demographics}

The demographic characteristics between studies were largely homogenous. This may be indicative of the type of people attracted to the VS lifestyle, or a product of the type of people who engage with research. 
Table 1. Comparison of the characteristics of the studies reviewed

\begin{tabular}{|c|c|c|c|c|c|c|}
\hline \multirow[b]{3}{*}{ Characteristic } & \multicolumn{6}{|c|}{ Study } \\
\hline & \multicolumn{2}{|c|}{ Brown \& Kasser (2005) } & \multirow{2}{*}{$\begin{array}{c}\text { Alexander \& Ussher } \\
(2012)\end{array}$} & \multicolumn{2}{|c|}{ Boujbel \& d'Astous (2012) } & \multirow{2}{*}{$\begin{array}{c}\text { Rich, Hanna \& Wright } \\
\text { (2017) }\end{array}$} \\
\hline & VS & Non-VS & & VS & Non-VS & \\
\hline$N$ & 200 & 200 & $\begin{array}{c}\text { 2,131 simplifiers } \\
(1,918 \text { answering } \\
\text { happiness question) }\end{array}$ & 344 & 267 & 571 \\
\hline \multicolumn{7}{|l|}{ Gender } \\
\hline Male & $34.5 \%$ & $34.5 \%$ & Not specified & $35.9 \%$ & $53.9 \%$ & $11.7 \%$ \\
\hline Female & $65.5 \%$ & $65.5 \%$ & Not specified & $64.1 \%$ & $46.1 \%$ & $88.3 \%$ \\
\hline Mean age & $\begin{array}{l}43 \text { years, } 5 \\
\text { months }\end{array}$ & 44 years & $\begin{array}{l}\text { Not specified, but } \\
\text { nothing unusual about } \\
\text { distribution }\end{array}$ & $\begin{array}{l}44 \text { years, } 6 \\
\text { months }\end{array}$ & $\begin{array}{c}35 \text { years, } 7 \\
\text { months }\end{array}$ & 45 years, 2 months \\
\hline \multicolumn{7}{|l|}{ Education } \\
\hline Postgrad & $37.5 \%$ & $21.5 \%$ & Not specified & \multirow{2}{*}{\multicolumn{2}{|c|}{$68.4 \%$ total sample }} & Not specified \\
\hline College degree & $39.5 \%$ & $30.5 \%$ & Not specified & & & Not specified \\
\hline Country of origin & USA & & $\begin{array}{l}\text { International } \\
\text { (developed nations) }\end{array}$ & Canada & & $\begin{array}{l}\text { Predominantly } \\
\text { Australia }\end{array}$ \\
\hline Wellbeing measure & $\begin{array}{l}\text { Affect Balance } \\
\text { Temporal Satis } \\
\text { Scale (Pavot, D }\end{array}$ & $\begin{array}{l}\text { iener et al. 1985) } \\
\text { tion with Life } \\
\text { er, \& Suh 1998) }\end{array}$ & $\begin{array}{l}\text { Single item } \\
\text { retrospective happiness } \\
\text { question }\end{array}$ & $\begin{array}{l}\text { Satisfaction wi } \\
\text { (Diener et al. } 1\end{array}$ & $\begin{array}{l}\text { Life Scale } \\
\text { 5) }\end{array}$ & $\begin{array}{l}\text { Satisfaction with Life } \\
\text { Scale (Diener et al. 1985) }\end{array}$ \\
\hline $\begin{array}{l}\text { Voluntary simplicity } \\
\text { measure }\end{array}$ & Self-identified & simplifier & $\begin{array}{l}\text { Participation invited if } \\
\text { participant fit a } \\
\text { definition given }\end{array}$ & $\begin{array}{l}\text { Self-identified } \\
\text { measure as val }\end{array}$ & $\begin{array}{l}\text { ith VS values } \\
\text { ity check) }\end{array}$ & $\begin{array}{l}\text { Voluntary Simplicity } \\
\text { Index (Leonard-Barton } \\
\text { 1981) }\end{array}$ \\
\hline Research design & Cross sectional, & etween groups & $\begin{array}{l}\text { Cross sectional, } \\
\text { descriptive }\end{array}$ & Cross sectiona & etween groups & $\begin{array}{l}\text { Cross sectional, } \\
\text { correlational }\end{array}$ \\
\hline Recruitment & $\begin{array}{l}\text { Newsletters, } \\
\text { magazines, } \\
\text { websites, } \\
\text { discussion lists }\end{array}$ & $\begin{array}{l}\text { List brokerage } \\
\text { firm }\end{array}$ & $\begin{array}{l}\text { Websites, blogs, and } \\
\text { organizations related to } \\
\text { VS }\end{array}$ & $\begin{array}{l}\text { Association } \\
\text { promoting VS }\end{array}$ & $\begin{array}{l}\text { Snowballing } \\
\text { and executive } \\
\text { MBA classes }\end{array}$ & $\begin{array}{l}\text { Websites, blogs, social } \\
\text { media, letterbox drop }\end{array}$ \\
\hline
\end{tabular}


For example, there was a predominance of females in the samples (Table 1). This is not uncommon in the voluntary simplicity literature (Breen Pierce, 2000; Huneke, 2005), however, it may not represent a genuine predominance of women within the lifestyle. Rather, it may be indicative of the online recruitment methods used. There is evidence to suggest that females are more likely to reply to online surveys than males (Smith, 2008).

There was also homogeneity in age and education level. Many scholars within the field argue that voluntary simplicity is the domain of those who could otherwise afford to live a higher consumption life if they chose to do so, due to higher levels of education and access to other resources (Craig-Lees \& Hill, 2002; Maniates, 2002). This may be important, since research suggests that the level of education attained can have an effect on subjective wellbeing (Kuppens, Easterbrook, Spears, \& Manstead, 2015). Regardless of this possible confound in the relationship, given the similarity of available demographics between the studies and the profile of voluntary simplicity described in the associated literature, it appears likely that all four studies reached their target population.

All four studies drew their samples from Western and developed nations, meaning that the results may not be applicable to less developed nations. However, the problem of research being restricted to westernised cultures is not confined to the VS literature and has been discussed by scholars for some time (cf. Suedfeld, 2016). For less developed nations, a simplified life is often a necessity rather than a choice (Alexander \& Ussher, 2012) and little is known about the existence of voluntary simplicity outside of developed nations. As such, the conclusions drawn may only be applicable to Western society.

\subsection{Measurement}

\subsubsection{Wellbeing measurement}

Similarities between the studies also extended to measurement of wellbeing, with life satisfaction being the most commonly used measure used in the four studies located (Table 1). Boujbel and d'Astous (2012) and Rich et al. (2017) employed the Satisfaction with Life Scale (Diener et al., 1985), perhaps the most widely used measure of life satisfaction. The SWLS demonstrates robust psychometric properties (Pavot \& Diener, 2008). Brown and Kasser (2005), however, measured life satisfaction using the Temporal Satisfaction with Life Scale (TSWLS) (Pavot, Diener, \& Suh, 1998). The TSWLS differs from the SWLS, in that it relates to past, present and future satisfaction. The scale has demonstrated good validity and reliability (Pavot et al., 1998) with the past, present and future factors being related but distinct (McIntosh, 2001). Brown and Kasser (2005) also measured affect balance, calculated by subtracting mean unpleasant affect scores from mean pleasant affect scores on the Diener and Emmons (1985) nine-item scale.

Alexander and Ussher (2012), however, measured wellbeing with a single item that asked those participants who had changed to a lifestyle of voluntary simplicity $(90 \%$ of the sample or 1,918 participants) if they were happier as a result. Participants could choose from four options, these being "much happier," "somewhat happier," "about as happy as I was previously," or "less happy." When considering the question of happiness, people may reflect on a variety of aspects of their lives to make such a judgment (Verhofstadt, Bleys, \& Van Ootegem, 2015). Further, there may be biases involved in the self-report of constructs such as happiness. For example, someone who has made a major change to their way of living may feel obliged to report that they are happier as a result, due to a post-decisional bias (Gerard \& White, 1983) or to eliminate any cognitive dissonance experienced (Festinger, 1985). 


\subsubsection{Identifying voluntary simplicity}

Where the studies did differ quite markedly was in their approach to identifying voluntary simplifiers (Table 1). Of the four studies reviewed, two required voluntary simplifiers to selfidentify as such (Boujbel \& d'Astous, 2012; Brown \& Kasser, 2005). This may be problematic, as participants may self-identify as simplifiers incorrectly, without a full understanding of what is meant by this term. Brown and Kasser (2005) acknowledged this and attempted to reconcile the problem by statistically testing for differences between VS and non-VS groups on two characteristics associated with the lifestyle in the literature, these being reduced income and reduced spending. The VS group differed from the non-VS group on both variables, suggesting their self-identification was valid. Boujbel and d'Astous (2012) also assessed the validity of the distinction between VS and non-VS participants in their study, using a measure of voluntary simplicity values (Shama \& Wisenblit, 1984).

Given these measures, it appears that both studies correctly identified their target populations. However, the level to which individuals were engaged in the VS lifestyle was typically not specified and nor was their length of involvement. This could be a limitation, since any association between VS and wellbeing may be tied to level or length of engagement. For instance, an extreme level of engagement, such as being entirely self-sufficient in a harsh environment (Vannini \& Taggart, 2012) may result in lower levels of satisfaction and affect. People new to the lifestyle may also face difficulties learning to adapt. Consistent with this possibility, a study with a sample of beginner simplifiers reported that some of the challenges faced may negatively impact their affect (Ballantine, Arbouw, \& Ozanne, 2011). Consequently, the putative association between VS and increased wellbeing may be underestimated when categorising simplifiers as a group without regard to level of engagement or stage of the simplifying process (e.g., novice simplifiers).

Rich et al. (2017) measured level of engagement in simplifying behaviours rather than comparing the outcome of self-identified simplifiers to non-simplifiers. However, there were issues in the way voluntary simplicity was measured in this instance. A revised version of Leonard-Barton's (1981) Voluntary Simplicity Index was used to measure participants' level of engagement in simplifying behaviours. As Craig-Lees and Hill (2002) point out, the index does not cover all of the aspects of voluntary simplicity discussed in the literature. As a result, the measure may be missing important aspects of the lifestyle that have a stronger association with wellbeing outcomes. The measure also fails to take into account in which stage of the process of simplifying participants were. It is therefore unknown if participants were experienced or lifelong simplifiers, or inexperienced beginners.

Alexander and Ussher's (2012) participants were provided with a definition of VS and participants were invited to partake in the study if they identified with the definition and viewed their lifestyle as long term. Many of the answers provided by the participants of the study fit the profile of simplicity as it is found in the literature, suggesting that the respondents were correctly identifying themselves as simplifiers. Perhaps the best indication that voluntary simplifiers were correctly identified within the four studies is the homogeneity of demographics discussed previously.

\subsection{Study design}

No longitudinal or experimental studies were identified in the review process (Table 1). The literature on the connection between voluntary simplicity and wellbeing is currently based on cross-sectional survey designs only, and, as such, causality between constructs cannot be inferred. Further, the research questions being investigated differed across the studies. 
Alexander and Ussher (2012) looked to gain insight into adherents of voluntary simplicity, with their survey containing 50 questions based on understanding of the lifestyle in the literature. Wellbeing was measured as one part of an overall picture of voluntary simplicity. On the other hand, Brown and Kasser (2005) looked at relationships between ecologically responsible behaviours and wellbeing, investigating mindfulness and voluntary simplicity as possible mediators in that relationship. Similarly, Boujbel and d'Astous (2012) investigated mediation, this time with voluntary simplicity as the independent variable, proposing a relationship between VS and life satisfaction with an ability to control one's desire to consume as a mediating factor. Mediation was also the target of investigation for Rich et al. (2017), this time with Deci and Ryan's (1985) three psychological needs being investigated as the mediator between VS and life satisfaction. Nonetheless, all four studies measured wellbeing as the dependent variable, thus potentially providing insight into the relationship between voluntary simplicity and wellbeing.

\subsection{Strengths and limitations}

Each of the studies was impacted by some limitations but, overall, the limitations of each study were somewhat mitigated by the strengths of others. For example, Brown and Kasser's (2005) study design included a non-simplifying sample that was matched on many demographic characteristics, with the exception of education level. Boujbel and d'Astous's (2012) nonsimplifying sample was not significantly different to their sample of simplifiers in level of education, somewhat mitigating any effect that education level may have had on wellbeing. Similarly, while Alexander and Ussher's (2012) study was descriptive in nature, it had a much larger sample size than those studies that utilised statistical testing. As such, the results obtained in the smaller samples are supported by the descriptive statistics obtained in the larger sample. Further, the studies comparing VS to non-VS samples were limited, in that level of engagement within the lifestyle was not measured. Rich et al. (2017) went some way to filling this gap by investigating simplifying behaviours on a continuum.

\subsection{Analysis of findings}

All four studies described a positive association between voluntary simplicity and increased wellbeing. In the case of life satisfaction, Brown and Kasser (2005) found that VS participants had a higher mean life satisfaction score $(M=4.47, S D=1.08)$ than their non-VS participants $(M=4.23$, $S D=1.12), t(398)=2.18, p=.03$. Similarly, Boujbel and d'Astous (2012) reported their VS participants also had a higher mean life satisfaction score $(M=27.95, S D 5.55)$ than their non-VS counterparts $(M=26.15, S D=5.25), t(609)=4.07, p<.001$ (standard deviations obtained from the authors). In addition to the mean differences reported between VS and non-VS participants, Rich et al. (2017) found a significant correlation between increased engagement in VS and increased life satisfaction ( $r=.15, p=.001$; note this figure is unpublished in the article). Further, Brown and Kasser described a significant difference between their VS participants $(M=2.05, S D=1.82)$ and non-VS participants $(M=1.60, S D=2.20)$ in affect balance scores, $t(398)=2.23, p=.026$.

Alexander and Ussher's (2012) survey asked participants who had transitioned to simplicity from more socially normative lifestyles if they were happier as a result. The response to this question prompted Alexander and Ussher to report that "the results overwhelmingly showed that the transition toward a simpler life increased happiness" (p. 76). Forty-six percent of participants reported being much happier after simplifying their lives, with $41 \%$ reporting they were somewhat happier. Only $12.7 \%$ reported being about as happy and $0.3 \%$ reported being less happy. 
In order to investigate whether the association between VS and wellbeing exists when the studies are pooled, a meta-analysis was performed on the three studies that used a statistical test to measure the association, making it possible to compare effect sizes. The meta-analysis was conducted using Comprehensive Meta-Analysis software (Version 3) and the standardised mean difference (Hedges g) was calculated (Figure 2). The three studies, incorporating four measures of the VS to wellbeing relationship, indicate that engagement in a VS lifestyle is commensurate with higher wellbeing scores, Hedges $g=.28$ (95\% CI 0.20, 0.37), $Z=6.279, p<.001$. The Q-statistic calculates if the studies in the meta-analysis share the same effect size. The Q-statistic in the current study was .896, and, as this is equal with the expected value of $Q$ (the 3 degrees of freedom) $p=.826$, this suggests all studies share the true effect size. Finally, the classic fail safe $N$ was calculated to address the problem of publication bias. This analysis revealed that an additional 36 studies with an effect size of zero would be required to render the current findings non-significant.

Figure 2. Forest plot of voluntary simplicity and wellbeing studies included in the metaanalysis

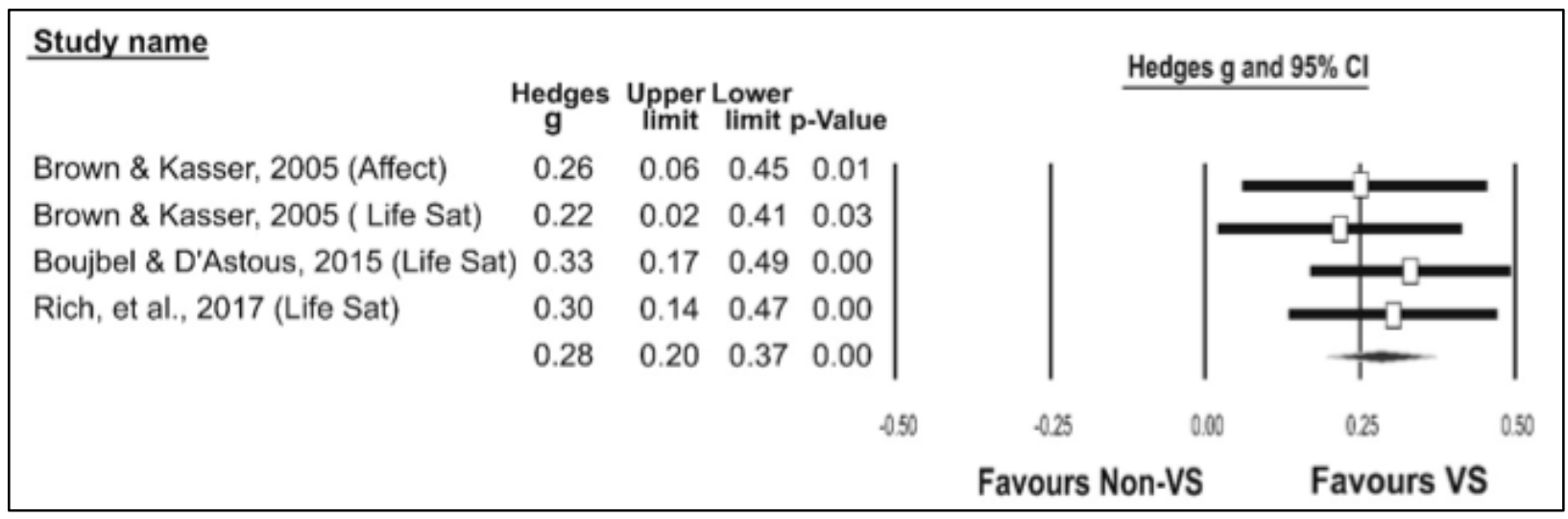

Brown and Kasser's (2005) measurement of affect balance is treated within the meta-analysis as a separate result. This was considered appropriate, given that positive and negative affect appear to be distinct from - but also related to - life satisfaction (Diener et al., 1985). Although there are only four studies within the meta-analysis, it should be noted that this is above the median of 3 in the Cochrane database (Davey, Turner, Clarke, \& Higgins, 2011). The use of the metaanalytic technique employed here is not intended to be definitive, rather, to statistically explore the putative associations within the small sample of research located.

\section{Discussion}

The aim of this study was to investigate whether empirical evidence exists to support a proposed link between voluntary simplicity and increased wellbeing. A systematic process, in line with the PRISMA guidelines (Moher, Liberati, Tetzlaff, Altman \& The PRISMA Group, 2009), was used to locate studies for inclusion. This methodology enabled us to build upon current knowledge, although the strict inclusion criteria both strengthened and weakened the conclusions that can be drawn. Because we included only studies that were subjected to the peer review process, the pool of available literature was reduced. Further, the requirement that studies should directly address wellbeing may have resulted in exclusion of rich qualitative information. Indeed, despite the literature around the VS lifestyle being rich and diverse, it appears that little empirical attention has been paid to the wellbeing outcomes of voluntary simplifiers. Only four 
studies could be found that specifically addressed the issue in question. Fortunately, each of these studies was reasonably robust, and, having synthesised currently available evidence, it is evident that some tentative conclusions can be drawn.

Most importantly, there does appear to be an association between engagement in voluntary simplicity and increased wellbeing. In the case of the meta-analytic investigation utilised, despite there being only four studies included, participant numbers were very high, and there was little variability in effect sizes, with the overall mean resting within the confidence intervals of each study. Moreover, none of the confidence intervals included zero. Although the effect may be considered small under Cohen's (1988) criteria, it should be noted that the life satisfaction scores reported by non-simplifying participants were also high. This is to be expected, as life satisfaction scores are generally negatively skewed, with respondents from Western societies generally reporting scores around 70\% of the scale maximum (Cummins, 2003). In order for a larger effect size to be achieved, then, the level of life satisfaction of simplifiers would need to approach extreme satisfaction. In other words, there may be a ceiling effect at play that current instruments are unable to resolve.

Despite this measurement problem, the results of the meta-analysis suggest that people who identify as voluntary simplifiers, or who engage in higher levels of simplifying behaviours, report higher levels of wellbeing than their already satisfied non-simplifying counterparts. To better clarify whether the lifestyle itself is responsible for that increase, it is suggested that future research focus on longitudinal studies. Such a design could involve recruiting people contemplating simplifying their lives and tracking them over a period of time, measuring their wellbeing. Alternatively, designs that prospectively measure the relationship between level of engagement in a VS lifestyle and wellbeing may enhance our understanding of the links between constructs.

Before this can happen, however, there needs to be consensus regarding the most appropriate conceptualisation of wellbeing. Although life satisfaction is arguably an important aspect of wellbeing, it is not the only aspect. Satisfaction in many forms is often mentioned in the voluntary simplicity literature, and it is possible that it is not always satisfaction with life that simplifiers are seeking. Words like "meaning and authenticity," "relationships and community," "balance and engagement" appear frequently in the discourse of simplifiers (Breen Pierce, 2000; Elgin, 2010; Zavestoski, 2002). If simplifiers are seeking meaning and authenticity in their lives, rather than other forms of life satisfaction, it may be critical to investigate these more eudaimonic aspects of wellbeing. In other words, are simplifiers finding what they seek? That is not to say that hedonic wellbeing should be ignored, rather it should be considered in harmony with eudaimonia. With this in mind, a more complex operationalisation of wellbeing, such as that provided by Seligman's (2012) PERMA model, may represent a more fruitful target of investigation.

Perhaps more importantly, there also needs to be consensus developed regarding whether researchers are correctly conceptualising and measuring voluntary simplicity. There are at least two issues that require resolution. Firstly, is voluntary simplicity one construct, or many constructs that share core features? Gregg (1936) proposed that simplicity "involves a deliberate organisation of life for a purpose... as different people have different purposes in life, what is relevant to the purpose of one person might not be relevant to the purpose of another" (p. 4). Gregg's words hint at the possibility of subcategories of voluntary simplicity. Indeed, researchers since Gregg's time agree that there are varying forms of the lifestyle (Elgin \& Mitchell, 1977; Etzioni, 1998), although these are typically poorly specified. 
This is important because, while the current study found a relationship between voluntary simplicity and wellbeing, it remains to be seen if that relationship holds within subcategories of the concept. For example, someone who grows their own food and makes their own furniture in order to experience self-determination may experience different outcomes to someone who restricts their consumption in order to work less and free their time for other pursuits. There may be different personal attributes that bring both of these people to these differing forms of simplicity, and those personal attributes may affect how they experience wellbeing. If there are indeed distinct categories of voluntary simplicity, then investigating the overarching construct of simplicity without due attention to such subcategories may be confusing matters.

Secondly, is the relationship between VS and wellbeing that this review has investigated dependent on level of engagement with the VS lifestyle? It is possible that level of engagement may play a role in increased wellbeing, as proposed by Boujbel and d'Astous (2012) and Rich et al. (2017). Currently, it is unknown if there is a level of engagement that, once reached, relates to specific positive outcomes. Perhaps there is a level of engagement wherein the lifestyle becomes burdensome! In order to understand how level of engagement may affect outcomes, a validated measurement instrument - that captures both the depth and type of involvement in subcategories of VS - is required.

The issues discussed do not negate the usefulness of the topic. Nor do they negate the current findings. This review demonstrates a connection between a loosely-bounded concept and increased life satisfaction. The next step requires clarification of the concept so that more work can be carried out across disciplines - fine-tuning our understanding of the potential impact of voluntary simplicity.

\title{
5. Conclusion
}

In this study, we investigated a theoretical - and often written about - link between engaging in a life of voluntary simplicity and increased wellbeing. Extant literature addressing this concept was located and synthesised with meta-analysis results suggesting such a link exists. However, many questions remain open for further investigation. Validated measures of more complex conceptualisations of wellbeing are urgently required, as are more sophisticated measures of type and depth of engagement with various aspects of voluntary simplicity. Once these conceptual and measurement issues are resolved, longitudinal studies could assist in deepening the work already achieved, thereby clarifying exactly how and why living a VS lifestyle can increase wellbeing. Aesop used storytelling to extol the value of simplicity, with countless retellings since. Empirical research appears to tell the same story, with one point of difference: the ending is yet to be written.

\author{
Authors \\ Stacey Ann Rich \\ La Trobe University \\ sarich@students.latrobe.edu.au \\ Sharon Hanna \\ La Trobe University \\ Bradley J Wright \\ La Trobe University
}




\section{Pauleen C Bennett}

La Trobe University

\section{Publishing Timeline}

Received 14 January 2017

Accepted 6 August year

Published 25 November 2017

\section{References}

Alexander, S., \& Ussher, S. (2012). The Voluntary Simplicity movement: A multi-national survey analysis in theoretical context. Journal of Consumer Culture, 12(1), 66-86. http://dx.doi.org/10.1177/1469540512444019

Australian Bureau of Statistics. (2007). Patterns of internet access in Australia, 2006. (cat. no. 8146.0.55.001). http://www.abs.gov.au/ausstats/abs@.nsf/mf/8146.0.55.001/

Ballantine, P. W., Arbouw, P., \& Ozanne, L. (2011). Learning to resist: The challenges faced by beginner voluntary simplifiers. Advances in Consumer Research, 39, 404-408. http://www.acrwebsite.org/volumes/1010308/volumes/v39/NA-39

Boujbel, L., \& d'Astous, A. (2012). Voluntary simplicity and life satisfaction: Exploring the mediating role of consumption desires. Journal of Consumer Behaviour, 11(6), 487-494. http://dx.doi.org/10.1002/cb.1399

Breen Pierce, L. (2000). Choosing simplicity: Real people finding peace and fulfillment in a complex world. Seattle, WA: Gallagher Press.

Brown, K. W., \& Kasser, T. (2005). Are psychological and ecological wellbeing compatible? The role of values, mindfulness, and lifestyle. Social Indicators Research, 74(2), 349-368. http://dx.doi.org/10.1007/s11205-004-8207-8

Cohen, J. W. (1988). Statistical power analysis for the behavioural sciences. (2nd ed.). Hillsdale, NJ: Lawerence Erlbaum Associates.

Craig-Lees, M., \& Hill, C. (2002). Understanding voluntary simplifiers. Psychology and Marketing, 19(2), 187-210. http://dx.doi.org/10.1002/mar.10009

Cummins, R. A. (2003). Normative life satisfaction: Measurement issues and a homeostatic model. Social Indicators Research, 64, 225-256. http://link.springer.com/article/10.1023/A:1024712527648

Daoud, A. (2011). The modus vivendi of material simplicity: Counteracting scarcity via the deflation of wants. Review of Social Economy, 69(3), 275-305. http://dx.doi.org/10.1080/00346764.2010.502832

Davey, J., Turner, R. M., Clarke, M. J., \& Higgins, J. P. (2011). Characteristics of meta-analyses and their component studies in the Cochrane Database of Systematic Reviews: A cross-sectional, descriptive analysis. BMC Medical Research Methodology, 11, 160. http://dx.doi.org/10.1186/1471-2288-11-160

Deci, E. L., \& Ryan, R. M. (1985). Intrinsic motivation and self-determination in human behaviour. New York, NY: Plenum. https://doi.org/10.1007/978-1-4899-2271-7

Delle Fave, A. (2014). Eudaimonic and hedonic happiness. In Encyclopedia of quality of life and wellbeing research (pp. 1999-2004). Dordrecht, Netherlands: Springer. http://dx.doi.org/10.1007/978-94-007-075353778

Diener, E., \& Emmons, R. A. (1985). The independence of positive and negative affect. Journal of Personality and Social Psychology, 47, 1105-1117. https://doi.org/10.1037/0022-3514.47.5.1105

Diener, E., Emmons, R. A., Larsen, R. J., \& Griffin, S. (1985). The Satisfaction with Life Scale. Journal of Personality Assessment, 49(1), 71-75. http://dx.doi.org/10.1207/s15327752jpa4901_13

Diener, E., Suh, E. M., Lucas, R. E., \& Smith, H. L. (1999). Subjective wellbeing: Three decades of progress. Psychological Bulletin, 125(2), 276-302. http://dx.doi.org/10.1037/0033-2909.125.2.276

Elgin, D. (2010). Voluntary Simplicity: Toward a way of life that is outwardly simple, inwardly rich (2nd ed.). New York, NY: William Morrow.

Elgin, D., \& Mitchell, A. (1977). Voluntary simplicity. Co-Evolution Quarterly, Summer. http://duaneelgin.com/voluntary-simplicity-report/ 
Etzioni, A. (1998). Voluntary simplicity: Characterization, select psychological implications, and societal consequences. Journal of Economic Psychology, 19(5), 619-643. http://link.springer.com/chapter/10.1007\%2F978-3-662-03900-7 1

Festinger, L. (1985). A theory of cognitive dissonance. Stanford, CA: Stanford University Press.

Gerard, H. B., \& White, G. L. (1983). Post-decisional reevaluation of choice alternatives. Personality and Social Psychology Bulletin, 9(3), 365-369. http://dx.doi.org/10.1177/0146167283093006

Gregg, R. (1936). The value of voluntary simplicity. Wallingford, PA: Pendle Hill.

Grigsby, M. (2004). Buying time and getting by: The voluntary simplicity movement. New York, NY: State University of New York Press.

Huneke, M. E. (2005). The face of the un-consumer: An empirical examination of the practice of voluntary simplicity in the United States. Psychology and Marketing, 22(7), 527-550. http://dx.doi.org/10.1002/mar.20072

Huta, V., \& Waterman, A. (2014). Eudaimonia and its distinction from hedonia: Developing a classification and terminology for understanding conceptual and operational definitions. Journal of Happiness Studies, 15(6), 1425-1456. http://dx.doi.org/10.1007/s10902-013-9485-0

Kahl, K. (2012). "My god wants me to live simply": The constructed selfhood of faith-based simple livers. Symbolic Interaction, 35(3), 249-266. http://dx.doi.org/10.1002/symb.20

Kuppens, T., Easterbrook, M. J., Spears, R., \& Manstead, A. S. R. (2015). Life at both ends of the ladder: Education-based identification and its association with wellbeing and social attitudes. Personality and Social Psychology Bulletin, 41(9), 1260-1275. http://dx.doi.org/10.1177/0146167215594122

Leonard-Barton, D. (1981). Voluntary simplicity lifestyles and energy conservation. The Journal of Consumer Research, 8(3), 243-252. http://dx.doi.org/10.1086/208861

Maniates, M. F. (2001). Individualization: Plant a tree, buy a bike, save the world? Global Environmental Politics, 1(3), 31-52. http://dx.doi.org/10.1162/152638001316881395

McDonald, S., Oates, C., Young, C., \& Hwang, K. (2006). Toward sustainable consumption: Researching voluntary simplifiers. Psychology E Marketing, 23(6), 515-534. https://doi.org/10.1002/mar.20132

McIntosh, C. N. (2001). Report on the construct validity of the Temporal Satisfaction with Life Scale. Social Indicators Research, 54(1), 37-56. http://dx.doi.org/10.1023/A:1007264829700

Moher, D., Liberati, A., Tetzlaff, J., Altman, D. G., The PRISMA Group. (2009). Preferred Reporting Items for Systematic Reviews and Meta-Analyses: The PRISMA Statement. PLoS Medicine, 6(7), e1000097. http://dx.doi.org/10.1371/journal.pmed.1000097

Pavot, W., \& Diener, E. (2008). The satisfaction with life scale and the emerging construct of life satisfaction. The Journal of Positive Psychology, 3(2), 137-152.

Pavot, W., Diener, E., \& Suh, E. (1998). The temporal satisfaction with life scale. Journal of Personality Assessment, 70(2), 340-354. http://dx.doi.org/10.1207/s15327752jpa7002 11

Rich, S. A., Hanna, S., \& Wright, B. J. (2017). Simply satisfied: The role of psychological need satisfaction in the life satisfaction of voluntary simplifiers. Journal of Happiness Studies, 18(1), 89-105. http://dx.doi.org/10.1007/s10902-016-9718-0

Ryan, R. M., \& Deci, E. L. (2001). On happiness and human potentials: A review of research on hedonic and eudaimonic wellbeing. Annual Review of Psychology, 52, 141-166. https://doi.org/10.1146/annurev.psych.52.1.141

Seligman, M. E. P. (2012). Flourish: A visionary new understanding of happiness and wellbeing. New York: NY: Free Press.

Shama, A., \& Wisenblit, J. (1984). Values of voluntary simplicity: Lifestyle and motivation. Psychological Reports, 55(1), 231-240. http://dx.doi.org/10.2466/pr0.1984.55.1.231

Shaw, D., \& Moraes, C. (2009). Voluntary simplicity: An exploration of market interactions. International Journal of Consumer Studies, 33(2), 215-223. http://dx.doi.org/10.1111/j.1470-6431.2009.00760.x

Shaw, D., \& Newholm, T. (2002). Voluntary simplicity and the ethics of consumption. Psychology $\mathcal{E}$ Marketing, 19(2), 167-185. https://doi.org/10.1002/mar.10008

Smith, G. (2008). Does gender influence online survey participation? A record-linkage analysis of university faculty inline survey response behavior. (ERIC Document Reproduction Service No. ED 501 717). http://files.eric.ed.gov/fulltext/ED501717.pdf 
Suedfeld, P. (2016). On the road from WEIRD to STEM, psychology hits a bump. Canadian Psychology/Psychologie Canadienne, 57, 60-64. http://dx.doi.org/10.1037/cap0000044

World Bank (n.d). Internet users (per 100 people). http://data.worldbank.org/indicator/IT.NET.USER.P2

Vannini, P., \& Taggart, J. (2012). Voluntary simplicity, involuntary complexities, and the pull of remove: The radical ruralities of off-grid lifestyles. Environment and Planning A, 45(2), 295-311. http://dx.doi.org/10.1068/a4564

Verhofstadt, E., Bleys, B., \& Van Ootegem, L. (2015). Reference-dependency of happiness ratings. Journal of Happiness Studies, 16(6), 1437-1454. http://dx.doi.org/10.1007/s10902-014-9567-7

Zavestoski, S. (2002). The social-psychological bases of anticonsumption attitudes. Psychology $\mathcal{E}$ Marketing, 19(2), 149-165. http://dx.doi.org/10.1002/mar.10007 